\title{
SECRETARIADO EXECUTIVO NO BRASIL: PROFISSÃO OU OCUPAÇÃO?
}

\section{EXECUTIVE SECRETARIAT IN BRAZIL: PROFESSION OR OCCUPATION?}

\section{Jéssica Oliveira Vieira}

Graduação em Secretariado Executivo Trilíngue pela Universidade Federal de Viçosa - UFV.

E-mail: jessicavieiraoliveira@gmail.com(Brasil)

\section{Débora Carneiro Zuin}

Doutorado em Estudos Organizacionais pela University of Edinburgh Business School (Reino Unido). Docente e Coordenadora do Curso de Secretariado Executivo Trilíngue da Universidade Federal de Viçosa - UFV.

E-mail: dzuin@ufv.br (Brasil) 


\section{SECRETARIADO EXECUTIVO NO BRASIL: PROFISSÃO OU OCUPAÇÃO?}

\section{RESUMO}

Este artigo apresenta o desenvolvimento e os resultados de um estudo que teve como objetivo geral averiguar o perfil do Secretariado Executivo no Brasil como profissão ou ocupação. Seus objetivos específicos propuseram apresentar o conceito de profissão e de ocupação; elaborar um quadro de referência, a partir da literatura consultada, evidenciando as características de uma profissão; fazer um levantamento historiográfico do Secretariado Executivo no Brasil; e verificar a importância e pertinência da criação do Conselho Federal de Secretariado (CFSEC). Dessa forma, foi realizada uma análise de vagas de emprego na região Sudeste, além de entrevistas com integrantes de associações da classe secretarial, sendo elas a Fenassece dois sindicatos estaduais; e um levantamento bibliográfico, utilizando-se a metodologia qualitativa. Visando uma interpretação e explicação dos dados obtidos, a análise de conteúdo foi empregada.

Palavras-chave: Secretariado Executivo, Profissão, Ocupação. 


\title{
EXECUTIVE SECRETARIAT IN BRAZIL: PROFESSION OR OCCUPATION?
}

\begin{abstract}
This article presents the development and results of an analysis that aimed to evaluate the profile of Executive Secretariat in Brazil as a profession or as an occupation. The general purposes were to present the concept of profession and occupation; to draw up a framework of reference, according to the existing literature to show the distinguishing characteristics of a profession; to conduct a historiographical survey of Executive Secretariat in Brazil; and to verify the importance of creating the Federal Secretariat Council. Therefore, an analysis of job vacancies was performed in the Southeast region of Brazil; some interviews with members of Secretariat associations as Fenassec and two syndicates were conducted; and a literature review was carried out using qualitative research. The content analysis was chosen in order to obtain a proper interpretation and explanation of the data.
\end{abstract}

Keywords: Executive Secretariat, Profession, Occupation. 


\section{INTRODUÇÃO}

Segundo Freidson (1986), o estudo das profissões data de antes do século XIX, quando era realizado, principalmente, por britânicos. Já depois da II Guerra Mundial, acadêmicos americanos dominaram esse campo de estudo por, pelo menos, vinte anos. No Brasil, os principais trabalhos foram desenvolvidos a partir dos anos de 1960 e 1970.

A abordagem das profissões é importante para entender o indivíduo e suas atribuições na esfera laboral, assim como o papel de cada profissão e sua contribuição para o desenvolvimento político, social e pessoal. Krause (1971) assinala que ocupações e profissões estão entre os principais mediadores na relação do indivíduo com a sociedade. Santana e Ramalho (2009) apontam que os autores clássicos do pensamento sociológico sempre abordaram a importância do trabalho e das relações que se construíram a partir dele para o entendimento da sociedade.

Com base na teoria das profissões e ocupações, este artigo visa analisar a área secretarial no Brasil, a partir de um levantamento realizado na região sudeste, a fim de averiguar se o Secretariado Executivo se trata de uma profissão ou ocupação. De acordo com Sabino e Marchelli(2009), a atividade secretarial tem suas origens no trabalho realizado pelos escribas. Bruno (2006) indica que a área passou por transformações propiciadas pelo avanço da tecnologia, pela inserção da mulher no mercado de trabalho, pelo desenvolvimento das atividades desempenhadas e pelo papel ocupado dentro das organizações, pela reivindicação dos direitos profissionais, assim como pelo reconhecimento em forma de lei.

Atualmente, o exercício da profissão secretarial, no Brasil, é regulamentado pela Lei $\mathrm{n}^{\mathrm{o}}$ 7.377/85, com alterações dadas pela Lei $\mathrm{n}^{\circ}$ 9.261/96, sendo a partir delas exigida a formação específica de nível superior em Secretariado Executivo, salvo em casos em que o profissional portador de qualquer diploma de nível superior comprove a execução das atividades inerentes à área por, pelo menos, trinta e seis meses, ou aos que possuem, pelo menos, cinco anos ininterruptos ou dez anos intercalados de exercício de atividades próprias de secretaria até a assinatura da lei.

Segundo informações do e-MEC, portal do Ministério da Educação (2014), o curso de Secretariado Executivo, seja em nível tecnológico ou bacharel, é oferecido em 228 instituições,públicas e privadas. Ainda de acordo com as Diretrizes Curriculares Nacionais para o curso de graduação em Secretariado Executivo, o estudante deve ter uma formação que lhe permita "desenvolver capacidade de análise, interpretação e articulação de conceitos e realidades inerentes à administração pública e privada". 
Apesar da grande vantagem em relação à área secretarial de outros países, onde não existem cursos superiores para formação de Secretários Executivos (Zuin, 2012), e dos avanços obtidos pela classe, ainda há muito a ser desenvolvido no campo legislativo. Segundo a Federação Nacional das Secretárias e Secretários (Fenassec, 2014), a categoria busca a criação do Conselho Federal de Secretariado, com vistas a fiscalizar o exercício das atribuições e a garantir o cumprimento do Código de Ética.

Dessa forma, este artigo propõe apresentar o conceito de profissão e de ocupação; elaborar um quadro de referência, a partir da literatura consultada, evidenciando as características de uma profissão; fazer um levantamento historiográfico do Secretariado Executivo no Brasil e verificar a importância do Conselho Federal de Secretariado. O objetivo geral, por sua vez, consiste no questionamento do Secretariado Executivo no Brasil comoprofissão ou ocupação. A pesquisa foi desenvolvida por meio da análise de entrevistas com integrantes de associações de classe, sendo elas a Fenassec e dois sindicatos estaduais; de listagem e análise de vagas de emprego direcionadas à região Sudeste e de levantamento bibliográfico. Empregou-se a metodologia qualitativa e a análise de conteúdo foi selecionada para interpretação dos resultados.Este artigo justifica-se pelo fato de levantar um questionamento ainda incipiente nas pesquisas da área, o qual - acredita-se -possa contribuir para a valorização e para o reconhecimento profissional, para o delineamento da identidade do Secretariado e para a verificação das possíveis implicações da criação do Conselho Federal de Secretariado.

\section{REFERENCIAL TEÓRICO}

\subsection{OS CONCEITOS DE PROFISSÃO}

Segundo Abbott (1988), apesar de as profissões derivarem da época medieval e, em alguns casos, terem origens na Antiguidade, as primeiras tentativas sistemáticas de estudá-las são do século XX. Já Freidson (1986) aponta que os primeiros trabalhos datam de antes do século XIX e que até 1940 os principais estudiosos do tema eram britânicos que enfatizavam como principais características das profissões seu conhecimento formal complexo, sua habilidade e sua abordagem ética.

Entretanto, depois do fim da II Guerra Mundial, foi a vez dos acadêmicos americanos dominarem esse campo de estudo por, pelo menos, vinte anos. Freidson (1986) destaca que 
em 1960, os estudos foram desenvolvidos nos Estados Unidos e no Reino Unido, com foco na influência política e cultural sobre as profissões, na relação entre profissões/política e elite econômica/Estado e na relação entre profissões/mercado e sistema de classes.

Pode-se inferir, a partir da literatura consultada, que profissão, de modo geral, é a afirmação de uma ocupação a partir do domínio de determinada área do conhecimento. Macdonald (1995) descreve profissão como ocupações baseadas em avançado, complexo, esotérico ou misterioso conhecimento.

Wilensky (1964), por sua vez, caracteriza profissão como a habilidade para desenvolver certa atividade com a jurisdição para tal. Ele aponta que o papel desempenhado por universidades e escolas de treinamento no processo de estabelecimento de uma profissão aparece antes mesmo de associações profissionais, e destaca o papel estratégico das universidades e dos professores: "Qualquer ocupação que deseje exercer autoridade profissional deve encontrar uma base técnica para isso, firmar uma jurisdição exclusiva e, em seguida, unir ambascom altos níveis de treinamento, convencendo o público de que apenas esses serviços são dignos de confiança”.Macdonald (1995) acrescenta que, se uma ocupação consegue estabelecer um curso superior como pré-requisito, isso é bom para os negócios e promove a garantia das habilidades do profissional.

Freidson (1995) defende que o trabalho das profissões se difere dos ofícios por ser uma especialização teoricamente fundamentada. Em seu levantamento, Freidson (1986) aborda que profissão pode ser mais que uma ocupação com prestígio. Dado seu conhecimento formal, ela também pode ser uma ocupação com formas especiais de proteção contra a concorrência no mercado de trabalho capitalista.

O referido autor elabora uma teoria do profissionalismo e destaca quatro características que descrevem uma profissão:

- Dentre os teoristas e estudantes da área, um conceito crítico baseia-se no acesso ao ensino superior e ao conhecimento formal que ele proporciona. É importante ressaltar o poder da capacidade profissional e que ela garanta a subsistência. Ou seja, a educação é um pré-requisito para a empregabilidade em posições particulares e o conhecimento formal cria barreiras para certas posições - outros que não tenham a mesma qualificação são excluídos de acedê-las;

- Uma organização coerente que assuma efetivamente um projeto de mercado, que obtenha sucesso em conquistar abrigo nesse mercado e controle para seus integrantes; 
- $\quad$ Exclui da categoria todas as ocupações em que o trabalho não depende de uma credencial baseada no ensino superior. Assim, apenas membros adequadamente credenciados poderiam executar as tarefas sobre as quais têm jurisdição;

- A credencial utilizada para amparar sua reserva de mercado de trabalho é criada por um programa de treinamento que se desenrola fora do mercado de trabalho, em escolas associadas à universidade.

Os pontos abordados acima descrevem as características necessárias a uma profissão para ser considerada como tal. Também cabe ressaltar o processo que deve ser desenvolvido até se obter ou não essa identidade, chamado de profissionalização.

Segundo Larson (1977) apud Macdonald (1995), profissionalização é uma tentativa de transformar uma ordem de escassos recursos, especialmente conhecimento e habilidades, em uma recompensa social e econômica.

Wilensky (1964) aponta que uma barreira à profissionalização de várias ocupações é a natureza e a estrutura da sua base do conhecimento e doutrina e que, se a base técnica consiste em vocabulário familiar para todos ou se a base é científica, mas tão limitada que pode ser aprendida como um conjunto de regras, então, a ocupação terá dificuldades reivindicando a jurisdição exclusiva.

Freeman (1997), em um estudo para identificar se a atividade de bibliotecário no Reino Unido era uma profissão, uma semiprofissão ou uma ocupação, aponta que o "Serviço Bibliotecário e Informativo" adquiriu a maioria das características necessárias ao processo de profissionalização, a partir dos seguintes fatores: Ocupação desempenhada em tempo integral; ensino superior e treinamento; reconhecimento oficial do Estado; código de ética e mecanismo interno de disciplina; trabalho altruísta para a comunidade; política geral e dominância numérica do setor de trabalho.

Já Wilensky (1964), ao examinar a história de dezoito ocupações, estabeleceu cinco passos para o processo de profissionalização, como pode ser observado no quadro abaixo.

\section{Quadro 1.Processo de Profissionalização segundo Wilensky (1964)}

\begin{tabular}{|l|}
\hline Processo de profissionalização \\
\hline Realização de uma atividade em tempo integral. \\
\hline Estabelecimento de uma escola de treinamento. \\
\hline $\begin{array}{l}\text { Formação de associações profissionais. Ativistas dentro dessas associações estão engajados em questões como } \\
\text { se a ocupação é ou não uma profissão, quais são as atividades inerentes a ela, como melhorar a qualidade dos }\end{array}$ \\
\hline
\end{tabular}


recrutados, entre outras. Separar os competentes dos não competentes para realização das atividades.

Luta política para garantir a proteção da área de trabalho através da lei e da sustentação do código de ética.

Estabelecimento do código de ética, usado para eliminar os não qualificados, regras para redução da competição interna e para proteção dos clientes, assim como, reforçar o serviço ideal.

Fonte: Elaborado pelas autoras.

Em relação ao segundo ponto, o autor estabelece que, mesmo que essas escolas não comecem dentro de universidades, elas sempre procuram manter contato com essas instituições e a desenvolver altos padrões de treinamento.

Já com referência à luta política, Wilensky (1964) coloca que "em casos onde a área de competência não é claramente exclusiva, o objetivo será a proteção do título”. Entretanto, ele acrescenta que licenças e certificação como armas na batalha para autoridade profissional são o menos importante dos eventos; ao contrário, a proteção legal é uma questão muito importante para novas profissões. Após levantamento bibliográfico empreendido dentre os principais teóricos da área, o presente trabalho desenvolveu um quadro de referência das profissões.

Quadro 2. Quadro de referência das profissões

\begin{tabular}{|ll|}
\hline Características das profissões & Autor \\
\hline & Wilensky (1964) \\
\hline Jurisdição exclusiva que garanta à profissão controle total legalmente estabelecido. & Abbott (1988) \\
\hline & Macdonald (1995) \\
\cline { 2 - 2 } & Wilensky (1964) \\
\hline Educação e treinamento específicos como pré-requisitos para a empregabilidade. & Freidson (1986) \\
\hline & Freeman (1997) \\
\hline Garantia da proteção da área de trabalho através de lei e sustentação do código de & Wilensky (1964) \\
\cline { 2 - 2 } ética. & \\
\hline \hline $\begin{array}{l}\text { Criação de associações ou organizações profissionais que assumam um projeto de } \\
\text { mercado. }\end{array}$ & Wilensky (1964) \\
\cline { 2 - 2 } & Freidson (1986) \\
\hline
\end{tabular}

Fonte: Elaborado pelas autoras.

Esse quadro visou compilar e cruzar alguns dos pontos apresentados por esses autores de modo a caracterizar uma profissão. Apesar de os primeiros estudos dessa área da Sociologia datarem de antes do século XIX, ainda não se evidencia uma definição única do que leva uma ocupação a tornar-se uma profissão ou do que caracteriza uma profissão. No 
entanto, observa-se convergência nos diferentes estudos. Esse quadro justifica-se, portanto, por reunir as teorias, gerando possivelmente, uma abordagem mais ampla.

\subsection{OCUPAÇÃO}

De acordo com Zuin (2012), definir ocupação é importante porque ela é usada para categorizar, delinear e medir o trabalho que as pessoas realizam. Segundo Watson (1995),essa importância deve-se também a seu papel como ferramenta sociológica, assim como seu valor para o titular da ocupação.

Para Hall (1969), uma ocupação é um papel social realizado por adultos que direta ou indiretamente produz consequências sociais e financeiras e que constitui um grande foco na vida destes. Como exposto por Zuin (2012), ao revisar as descrições de ocupação, a principal definição está fortemente ligada a uma ideia de atividade remunerada. Damarin (2006) sintetiza que ocupações são entendidas como mecanismos para dividir, alocar e direcionar a força de trabalho.

A fim de categorizar e classificar as ocupações há as classificações de ocupações, dentre elas, a Classificação Brasileira de Ocupações (CBO). Segundo Scott \& Marshall (2009), as classificações de ocupações são formas de agrupar e classificar empregos e ocupações, e, de acordo com informações do Ministério do Trabalho e Emprego (MTE, 2014), as classificações surgem da agregação de situações similares de emprego ou trabalho.

A CBO é o instrumento normalizador do reconhecimento, da nomeação e da codificação dos títulos e conteúdos das ocupações em âmbito nacional, cuja finalidade é a identificação destas. (MTE, 2014). Na listagem da CBO, é possível encontrar a classificação referente ao Secretário ou Secretária em três grandes grupos: Grupo 1 - membros superiores do poder público, dirigentes de organizações de interesse público e de empresas, gerentes; Grupo 2 - profissionais das ciências e das artes; e Grupo 3 - técnicos de nível médio.

\subsection{HISTÓRIA DO SECRETARIADO NO BRASIL}

Apesar de não haver muitos registros sobre a origem da atividade secretarial, alguns autores citam que o profissional de Secretariado tem seu primeiro representante ainda na Idade Antiga, com os escribas. Segundo Nonato Jr. (2009), a principal característica desses sujeitos era a atividade de assessorar. Bruno (2006) ressalta que o destino dessa atividade 
trilha pelos caminhos do conhecimento, e que o Secretário Executivo está sempre atuando ao lado de quem tem uma posição de poder para tomada de decisão.

De acordo com Nonato Jr.(2009), o avanço quantitativo e qualitativo dos profissionais de Secretariado no mundo do trabalho ocorreu em consonância com o desenvolvimento da tecnologia e dos paradigmas da ciência. Bruno (2006) destaca que "o profissional de secretariado acompanha as mudanças impostas pelo processo da globalização, bem como a horizontalizarão gerencial necessária para a continuidade das organizações numa economia competitiva e agrega novas competências ao seu perfil".

No que se refere às associações de classe, Figueiredo (1987) afirma que o Clube das Secretárias, que em 1970 se transformou na Associação das Secretárias do Rio de Janeiro, foi a primeira associação civil fundada com o objetivo de reunir e agrupar a classe, visando à conscientização e ao aprimoramento profissional.

Segundo informações do site da Fenassec, em 1976 foi criada a Associação Brasileira de Entidades de Secretárias. Bruno (2006) destaca que essa associação garantiu conquistas à classe como:

A Lei $\mathrm{n}^{\mathrm{o}}$ 6.556/78, de 5 de setembro de 1978, primeiro documento a reconhecer a profissão secretarial. Bruno (2006) reforça que essa lei forneceu dispositivos para que as delegacias regionais de Trabalho ficassem responsáveis pelos registros da profissão, porém não havia mecanismos de sua obrigatoriedade no cumprimento pelas organizações. Nonato Jr. (2009) ressalta que "nesta lei o trabalho de Secretariado ainda era tomado por atividade e não por profissão";

- Elaboração do Código de Ética da Secretária brasileira.

- $\quad$ A Lei $n^{\circ} 7.377 / 85$, de 30 de setembro de 1985 regulamentando a profissão de secretariado e estabelecendo a distinção entre Secretariado e Secretariado Executivo. Nonato Jr. (2009) aponta que, com as leis de regulamentação, a profissão de Secretariado passou a ter registro feito nas Delegacias Regionais de Trabalho e gerência profissional das entidades estaduais, no entanto, a Fenassec (2014) afirma que isso tem ocasionado os mais díspares julgamentos, prejudicando a classificação ideal dos Secretários.

Em abril de 1987, a Portaria $n^{\circ} 3.103$ determinou e reconheceu o profissional de secretariado como categoria profissional diferenciada, o que possibilitou uma melhor organização da categoria secretarial devido ao enquadramento sindical. Segundo Bruno (2006), com a criação dos sindicatos, em número superior a cinco no território nacional, foi possível a representatividade nacional da categoria por meio de uma federação. Assim, o que 
sucedeu a organização dos sindicatos estaduais foi a criação da Fenassec, em 1988. Segundo dados do site da Federação, ela é uma entidade sindical de segundo grau, de direito privado, sem fins lucrativos, representante da categoria secretarial em todo o território nacional.

Com as novas demandas do mercadoera também necessário que houvesse uma padronização na elaboração de currículos dos cursos de graduação para a formação acadêmica em Secretariado Executivo de nível superior.NonatoJr.(2009) salienta que, apesar de o primeiro curso de Secretariado Executivo no Brasil ter sido criado em 1969, foi na década de 1990 que a educação superior em Secretariado Executivo se expandiu.

Bruno (2006) aponta que em 1992, durante o XVIII Congresso Nacional de Secretariado, os participantes deliberaram sobre a necessidade da criação de um currículo para a formação acadêmica em Secretariado Executivo de nível superior. A autora relata que o reflexo desse trabalho foi a publicação do Parecer CNE/CES n ${ }^{\circ}$ 146, de 3 de abril de 2002, queaprovou as diretrizes curriculares nacionais dos cursos de graduação em Secretariado Executivo. A partir dessas diretrizes, foi possível regulamentar a educação superior em Secretariado Executivo e formar um bacharel com características semelhantes, necessárias ao desempenho das atividades próprias da área secretarial.

Atualmente, a Fenassec é o órgão máximo de representatividade da área secretarial existente no país, entretanto, ainda busca a criação do Conselho Federal de Secretariado, que seria o regulador e fiscalizador da profissão com prerrogativas jurídicas para tal. De acordo com a Fenassec (2014) esse conselho "tem por atribuição orientar, disciplinar e fiscalizar o exercício da profissão, bem como supervisionar o cumprimento e a aplicação do Código de Ética Profissional".

Queiroz (2003) ressalta que a Federação e seus sindicatos filiados iniciaram um movimento para a criação dos conselhos regionais e federal de Secretariado em face da ineficiência, do despreparo, do desinteresse e até do descumprimento da Lei pelas Delegacias Regionais do Trabalho. Assim, em 1997, foi apresentado ao Congresso Nacional, o Projeto de Lei do Senado ${ }^{\circ} 91$ para a Criação do Conselho Federal de Secretariado e dos Conselhos Regionais de Secretariado.Queiroz (2003) pontua que o projeto foi aprovado por unanimidade no Congresso e enviado à sanção presidencial em abril de 2000, tendo sido vetado integralmente pelo Presidente da República sob o fundamento de vício de iniciativa.

Em 2013, o Senador Marcos Montes apresentou o Projeto de Lei nº 6455/13 que dá nova redação à Lei $\mathrm{n}^{\circ} 7.377$, de 30 de setembro de 1985, e autoriza a criação do CFSEC e dos CRSEC, cujo teor foi considerado inconstitucional pela Fenassec, conforme nota veiculada em rede social, no dia 15 de maio de 2014. 


\section{METODOLOGIA}

Segundo Lakatos e Marconi (2011), o que distingue o conhecimento científico do senso comum não é a veracidade, nem a natureza do objeto de estudo, e sim a forma, o modo ou o método empregado. A metodologia, portanto, trata das técnicas utilizadas para investigar a realidade de modo científico. O presente artigo adota a metodologia qualitativa. De acordo com Alves-Mazzotti (2004), as pesquisas qualitativas caracterizam-se por sua diversidade e flexibilidade. Denzinet al. (2006) apontam que a ênfase dessa metodologia são os significados que não são examinados ou medidos experimentalmente.

Um dos métodos de coleta de dados empregado foi o levantamento bibliográfico. Para isso, foi realizada uma busca em textos científicos, livros e estudos relacionados à teoria das profissões, assim como do conceito de ocupação. Já para obtenção dos dados relativos à área secretarial, foi feita uma consulta do histórico do Secretariado em livros, artigos científicos, leis e decretos referentes a essa área e no site da Fenassec.

Também foram realizadas três entrevistas semiabertas com integrantes de órgãos de classe, sendo uma da Fenassec e duas de sindicatos estaduais, nos meses de julho, setembro e outubro de 2014, a fim de verificar o segundo ponto que caracteriza uma profissão, à luz da teoria de Freidson (1986) - uma organização que assuma efetivamente um projeto de mercado, conquistando abrigo nesse mercado, controle e sinecura para seus integrantes; e discorrer sobre a criação do Conselho Federal de Secretariado. Lakatos e Marconi (1991) apontam que a entrevista é um procedimento utilizado na investigação social, para a coleta de dados ou para ajudar no diagnóstico de um problema social.

Por fim, com o intuito de levantar se há exigência do curso superior em Secretariado Executivo para oportunidades destinadas a essa área, foi realizado um levantamento de 51 vagas de emprego direcionadas às Secretárias e aos Secretários Executivos da região Sudeste do Brasil, divulgadas no sitevagas.com.br.A delimitação da região foi intencional, visto que se acredita que a maior disponibilidade de vagas para a área secretarial esteja concentrada no sudeste do Brasil. O recorte das vagas foi realizado entre os meses de dezembro de 2013 e abril de 2014. A pesquisa no site foi desenvolvida a partir da busca por "secretariado, secretário ou secretária”.

Por último, para que fossem possíveis uma interpretação e uma explicação adequada dos dados obtidos, foi utilizada a análise de conteúdo. Segundo Bardin (2011) essa técnica tem por finalidade a descrição objetiva e sistemática do conteúdo manifesto na comunicação, 
permitindo produzir inferências do conteúdo de um texto. Fonseca (2009) aponta que a inferência nesse caso é considerada uma operação destinada a extrair conhecimentos da mensagem analisada. Portanto, a partir da análise de conteúdo, propôs-se examinar os dados obtidos, categorizando-os e interpretando-os de forma qualitativa.

\section{DISCUSSÃO DOS RESULTADOS}

\subsection{ANÁLISE DAS VAGAS DE EMPREGO}

Como exposto anteriormente, foram coletadas e analisadas 51 vagas de emprego. A fim de categorizá-las, elas foram distribuídas nos grandes grupos, Secretariado; Superior em Administração; Secretariado ou Administração; Superior em Secretariado ou Letras; Outros cursos dentre eles Secretariado, Letras ou Administração; Formação de nível superior sem especificação e Outros, de acordo com as exigências de cada vaga.

Do total de vagas analisadas, apenas $2 \%$ não apresentavam nenhuma exigência referente à escolaridade, e sim aos conhecimentos inerentes ao cargo, como pacote Office, redação e arquivo. Mesmo assim, é importante ressaltar que o trabalho do secretário não se limita a essas atividades. De acordo com a lei de regulamentação 7.377/96, são atribuições inerentes a esse profissional: planejamento, organização e direção de serviços de secretaria; assistência e assessoramento direto a executivos; coleta de informações para a consecução de objetivos e metas de empresas; redação de textos profissionais especializados, inclusive em idioma estrangeiro e interpretação e sintetização de textos e documentos.

Outras 14\% não evidenciavam um curso superior específico, tendo como exigência, formação completa em nível superior ou em andamento. Macdonald (1995) expõe que se uma ocupação consegue estabelecer um curso superior como pré-requisito, isso é bom para os negócios e promove a garantia das habilidades do profissional. Nesse caso, todas as vagas exigiam formação superior, entretanto, devido aos diferentes cursos apresentados nas outras vagas, não se pode afirmar que essa formação fosse específica em Secretariado Executivo. Portanto, ao invés de fortalecer a área, esse fato pode apresentar-se como uma debilidade, já que desfavorece os estudantes de Secretariado Executivo.

Já 12\% tinham como requisito a formação superior em Secretariado ou Letras, ratificando a problemática já vista na área pública, em que esses profissionais podem 
prestar concurso público para o cargo de Secretário Executivo, segundo disposto na Lei $\mathrm{n}^{\circ}$ 11.091/2005, sem terem graduação na área.

Dentre as vagas, $18 \%$ requeriam formação completa em Secretariado ou Administração. Enquanto isso, 6\% exigiam formação exclusiva em Administração. Bruno (2006) aponta que o profissional de secretariado "tem uma formação generalista na área de administração sabendo planejar, organizar, dirigir e controlar os processos necessários para assessorar o administrador e/ou uma equipe de trabalho". Assim, pode-se inferir que a formação e atuação do secretário, que abrange certos campos da Administração, leve o empregador ao desconhecimento do trabalho realizado por uma e por outra área.

Todavia, Wilensky (1964) afirma que "qualquer ocupação que deseje exercer autoridade profissional deve encontrar uma base técnica para isso e afirmar uma jurisdição exclusiva, [...] convencendo o público que apenas esses serviços são dignos de confiança". Freidson (1986) corrobora essa afirmativa ao descrever que profissão também pode ser uma ocupação com formas especiais de proteção contra a concorrência no mercado de trabalho.

Outras 19\% das vagas apresentavam a possibilidade de formação em diferentes cursos, dentre eles Relações Internacionais, Automação de Escritório, Marketing, Comunicação Social, Economia, Pedagogia e Recursos Humanos. Nessa categoria sempre estavam presentes um dos três cursos: Letras, Secretariado ou Administração.

Contrapondo os dados obtidos com a teoria, acentua-se que a principal característica das profissões está pautada no conhecimento formal. Freidson (1986) aponta que a educação é um pré-requisito para a empregabilidade em posições particulares e que o conhecimento formal cria barreiras para certas posições. Outros que não tenham a mesma qualificação são excluídos de acedê-las. Contrariamente, na área secretarial, o levantamento aponta que em 49\% (12\% Secretariado ou Letras; $18 \%$ Secretariado ou Administração; $19 \%$ outros cursos) das vagas era possível ter formação superior em Secretariado ou outra área e, em 6\%, formação exclusiva em Administração.

Essa pluralidade na formação para cargos de Secretária/Secretário Executivo pode ser pautada na própria descrição da $\mathrm{CBO}$, que dispõe que o exercício da ocupação de Secretário Executivo "requer curso superior em Secretariado e áreas afins" [ênfase adicionada]. Apesar das descrições da $\mathrm{CBO}$ serem de ordem administrativa, sem se estender as relações de trabalho, esse fato contrapõe a Lei ${ }^{\circ}$ 7.377/1985, alterada pela Lei $n^{\circ}$ 9.261/1996.

Já as vagas que requeriam formação específica em Secretariado, fosse em nível técnico ou superior, somavam 29\%. A partir da análise geral dos dados, verifica-se que o 
Secretariado ainda não atingiu abrigo no mercado de trabalho, nem jurisdição exclusiva, assim como se pôde evidenciar o desconhecimento dos empregadores sobre as atribuições de distintas profissões em relação à área secretarial e sobre as leis que regem este campo de atuação.

\subsection{ANÁLISE DAS ENTREVISTAS}

Um dos objetivos das entrevistas era verificar a importância do Conselho Federal de Secretariado (CFSEC) para a categoria, assim como processo de desenvolvimento daquele.

Quando questionada sobre o processo de criação do CFSEC, a Entrevistada 1 expôs que:

Está parado nas autoridades maiores [...], está percorrendo várias instâncias da política mesmo, mas não está indo pra frente não [...] a Bernadete (Presidente da Fenassec) tá tentando, a Fenassec tá envolvidíssima, mas o negócio não tá caminhando não", ela ainda acrescenta que "parece que não é interessante para o, para o país (Entrevistada 1).

A Entrevistada 2 diz sobre esse processo:

Eu entendo, do meu ponto de vista que ele não, que ele está paralisado", entretanto, contrapõe o fato de a Federação estar diretamente envolvida na luta política: "As ações que eu vi elas não foram por iniciativa direta das entidades de classe, mas sim de deputados de uma forma isolada, atendendo demandas de outras instituições (Entrevistada 2).

A Entrevistada 1 coloca que na época, o então Presidente, Fernando Henrique Cardoso:

"Falou que se colocasse esse tipo de Conselho, muitas pessoas iriam perder emprego". Essa afirmação pode ser explicada pelo fato de que, com o Conselho, o exercício de um trabalhador não qualificado para tal seria considerado ilícito.

A Entrevistada 1 também caracterizou a situação como um "descaso da política mesmo" e reafirmou que, para as autoridades, o "Conselho poderia prejudicar muito os trabalhadores, empregados num contexto geral [...]. Eles acharam que deixando quieto ficaria melhor (Entrevistada 1).

Entretanto, a própria Entrevistada 1 faz o seguinte questionamento: "E quem tem o curso e tem outro atuando no lugar dele, o que não é justo, neh?". "Fica aí a mercê da vontade 
de quem queira empregar qualquer profissional pra secretário, neh?” Esse posicionamento vai ao encontro do observado na análise das vagas de emprego, em que apenas $29 \%$ exigiam formação exclusiva em Secretariado.

Já a Entrevistada 2 atesta que "falta para o movimento secretarial articulação política", acrescentado que "a categoria secretarial, ela essencialmente, ela foi prática a sua vida inteira, e ela não foi um organismo, assim, dentro do processo do mercado de trabalho que estamos inseridos". Ela ainda analisa o papel das lideranças sindicais: "Nós viemos de um roteiro, eh, muito mais prático, da essência da profissão, nós não fomos suficientemente articulados politicamente pra que a gente batalhasse a continuidade desse projeto". Acrescenta que "a gente carece de política dentro do movimento sindical, secretarial, pra que a gente possa fazer com que esse projeto avance", e conclui que "eu entendo que ele só vai ser, $e h$, que conseguiremos esse conselho se nós formos articulados politicamente junto ao poder mesmo executivo".

Wilensky (1964), ao descrever o processo de profissionalização ressalta, justamente, que é preciso luta política para garantir a proteção da área de trabalho por meio da lei e da sustentação do código de ética.

A Entrevistada 3, por sua vez, atesta que "a proposta de projeto, que a Federação encaminhou [...] tá desde 2010 no Ministério do Trabalho" e que "segundo o Ministério do Trabalho tem mais de 50 pedidos de criação de Conselho lá dentro.” Dessa forma, ao contrário do exposto pela Entrevistada 2, a Entrevistada 3 afirma que a Federação está envolvida nas ações para criação do CFSEC. A Entrevistada 3 descreve o andamento do processo:

O Ministério do Trabalho [..] encaminhou à Casa Civil uma exposição de motivos interministeriais" e "essa exposição de motivos, ela gerou várias reuniões de um grupo de trabalho, formado por técnicos do próprio MTE, da Casa Civil e do Planejamento [...] e chegaram já a conclusão dos critérios para serem criados Conselhos Profissionais (Entrevistada 3).

A Entrevistada 3 ainda coloca que:

O Ministério do Trabalho disse que nós seríamos um dos primeiros conselhos a serem criados, porque nós temos a profissão regulamentada, [...], porque nós temos formação específica pra atuação, somos uma categoria direcionada". Ela também expõe que agora é preciso conseguir uma "audiência pública pra discutir por, quais os entraves pra criação desse nosso Conselho, se a gente atende a todos os critérios (Entrevistada 3).

Já sobre os benefícios do CFSEC, a Entrevistada 1 relatou que, com ele, "a valorização da profissão seria muito maior", já que ele é que "pode fiscalizar, dizer se você pode atuar 
como secretário ou não". Além disso, ela acrescenta que "se você está formado em Letras, Psicologia você não pode atuar não, aí multa a empresa e multa a pessoa".

A Entrevistada 2 expôs que "a não criação do conselho ele prejudica a classe e o secretariado", apontando os mesmos problemas evidenciados pela Entrevistada 1: "Porque hoje em dia nós temos muitos profissionais no exercício da profissão sem buscar essa formação" (em Secretariado). Ela indica ainda que "o Conselho de Secretariado ele seria um regulador para o ingresso e para que, para que aqueles que fossem de fato interessados, entrassem, eh, buscassem essa formação específica em secretariado pra poder atuar no mercado de trabalho".

\section{A Entrevistada 3 acrescentou que:}

Nós temos aí $\mathrm{N}$ instituições de ensino que formam profissionais e temos também aí $\mathrm{N}$ mais $\mathrm{N}$ pessoas atuando sem ter essa qualificação, não é? Sem ter essa formação específica em Secretariado. A não criação do conselho vai dar continuidade pra que profissionais não habilitados continuem atuando como secretário (Entrevistada 3).

Ela complementa que dessa forma "as empresas perdem pela qualidade dos serviços prestados, porque quem entende de técnicas secretariais são as pessoas que tem a formação específica em Secretariado".

A resposta das entrevistadas nos remete aos estudos de Freidson (1986), quando afirma que a literatura mais recente foca na influência política e cultural sobre as profissões. Entretanto, e como observado no levantamento das vagas de emprego, a Entrevistada 1 afirma que "infelizmente, sem o conselho a gente não tem como barrar isso, neh? Nós não temos autoridade pra fazer isso, nem os nossos sindicatos no Brasil, nem a Federação".

Além de expor as vantagens do Conselho no meio laboral, a Entrevistada 1 também coloca quais seriam, em sua opinião, os benefícios para o delineamento da profissão perante a sociedade: "As pessoas vão ver que a profissão é séria, que o secretariado tem registro, que tem que ter uma atuação diferenciada". A resposta da Entrevistada 1 vai ao encontro do que Wilensky (1964) apresenta: "Onde a área de competência não é claramente exclusiva, a proteção legal do título será o objetivo".

Ao cruzar os dados obtidos na análise das vagas com as entrevistas e o referencial teórico, pode-se evidenciar que o CFSEC garantiria à área secretarial meios mais eficazes de controle e fiscalização, além de proporcionar proteção legal e maior reconhecimento ao profissional.

Também pretendeu-se verificar com as entrevistas a concepção de jurisdição. A ideia de jurisdição das profissões foi empregada por Wilensky (1964) e abrange o controle 
total, legalmente estabelecido, a um campo de atuação. Foi perguntado às entrevistadas se elas acreditavam que o Secretariado Executivo tenha controle da sua área.

A Entrevistada 1 expôs que "não tem o controle não, exatamente por isso, porque não tem um órgão máximo para que possa fazer esse controle". Ela afirma que "não tem esse controle, até porque o próprio secretário, a própria secretária, ela não vai lá no Ministério, lá no trabalho pra fazer seu registro profissional". A Entrevistada 1 testemunhou como ela mesma atuava como uma divulgadora da profissão: “Onde eu passava eu falava, aqui, oh, na minha carteira tem o registro profissional, aí o pessoal falava assim: Uai, mas secretária tem registro? Eu falei tem, assim como engenheiro, como médico, como administrador, nós somos uma profissão, olha aqui meu registro".

A Entrevistada 2 também aponta que o Secretariado Executivo não tem controle do seu campo de atuação e fala sobre o órgão que deveria fiscalizar essa área de atuação:

É, não tem controle porque ele é fiscalizado, ele deveria ser fiscalizado pelo
Ministério do Trabalho e Emprego, em cima da Lei de Regulamentação da
Profissão, o MTE não tem gente suficiente e não se interessa em fiscalizar a
profissão de secretariado porque eles têm muitas outras atribuições e isso faz com
que o mercado de secretariado, ele fique desvirtuado (Entrevistada 2).

As respostas da Entrevistada 1 sugerem que o controle não depende somente das associações e entidades de classe, mas também de cada trabalhador, porém mostra que os próprios secretários e secretárias não têm participação nessa busca. As respostas da Entrevistada 2também apontam que o problema está na falta de fiscalização por parte do MTE. Ambas afirmam que o Secretariado Executivo, atualmente, não tem controle ou jurisdição do mercado de trabalho.

A Entrevistada 3, por sua vez, contrapõe as outras respostas ao levantar que a partir das Diretrizes Curriculares Nacionais o Secretariado Executivo tem controle da sua área de atuação. Além disso, expôs que através da "Resolução 03 de 2005 [...] as instituições são obrigadas a obedecer e a lançar no mercado de trabalho profissionais com o perfil que foi estabelecido". Apesar disso, a própria Entrevistada 3 afirma que "a gente tá prejudicado, principalmente de ter profissionais de outras áreas atuando livremente como, eh, sem nenhuma advertência, sem nenhuma punição e as empresas estão, automaticamente, contratando esses profissionais também e levando ao descaso a lei de regulamentação”.

Por conseguinte, verifica-se que o Secretariado Executivo não tem jurisdição. Mesmo que haja diretrizes específicas para a padronização da formação acadêmica, no mercado de trabalho levantou-se que o Secretário Executivo ainda é prejudicado pela atuação de outros profissionais. 
Wilensky (1964), assim como Freidson (1985), descreve como parte do processo de profissionalização a criação de associações ou organizações profissionais que assumam um projeto de mercado para controle da área. Vale salientar que essas associações só existem com o apoio dos trabalhadores. Então, as entrevistadas foram questionadas sobre o que os sindicatos e a Federação anseiam dos Secretários e Secretárias Executivas.

A Entrevistada 1 descreveu a falta de engajamento dos trabalhadores: "A maioria das secretárias e secretários que formam não vão buscar o registro não”. Ela acrescenta que “muitas vezes ele tem até vergonha de dizer que é secretário, sendo que ele luta pra ser e tudo mais".

Já a Entrevistada 2 apontou o que o Sindicato busca "qualificar esse profissional, garantindo pra ele a melhor prestação de serviço, a melhor assessoria e que ele seja empregado como tal, como profissional de secretariado e não em outras funções como assistente, assessores porque essas nomenclaturas denigrem a, o ingresso, a visibilidade da profissão no mercado de trabalho"

A Entrevistada 3 relata:

O que falta dos profissionais que eu entendo, da grandessíssima maioria é comprometimento. Comprometimento em relação à nossa profissão, em relação à nossa representatividade, neh. Infelizmente, os sindicatos, [...] a grande maioria, são sindicatos fracos de representatividade e isso por culpa da própria categoria, dos próprios profissionais (Entrevistada 3).

Wilensky (1964) expõe, exatamente, a importância dos próprios trabalhadores para o reconhecimento da profissão: "finalmente muitas ocupações vão afirmar reinvindicações para o status profissional, e verificar que essas reinvindicações não dependem de ninguém, mas delas mesmas". Sendo assim, fica evidente a importância dos sindicatos e organizações, assim como a participação dos profissionais para valorização e fortalecimento dos mesmos.

Já sobre os sindicatos, a Entrevistada 1 aponta que "o pessoal não se envolve com o que é importante pra categoria: reunião, o que tá acontecendo no meio, neh, no meio profissional", relatou que o trabalho realizado pelos sindicatos "é um trabalho de ideologia, de amor, de acreditar na profissão". E quando perguntada sobre o que as associações anseiam dos secretários e secretárias ele relatou que: "Nós gostaríamos muito que, mas muito, que a categoria se envolvesse mais com ela mesma”.

Para a Entrevistada 3, "os sindicatos são fracos por falta de contribuição, por falta de ajuda dos próprios profissionais", e relata: "O que falta e o que eu espero dos profissionais é essa maior contribuição. A mesma Entrevistada 3 declara: “A gente atua junto aos centros decisórios, somos uma profissão reconhecida, nós temos tudo, neh, tudo pra valorizar a 
profissão e a categoria, mas infelizmente, eu espero que os profissionais se conscientizem disso".

Assim, entendeu-se que não há muita participação dos trabalhadores nas questões tangentes à área, também pôde-se averiguar que essa participação é essencial para o título de profissão, conforme Wilensky (1964).

Como o objetivo principal deste trabalho era averiguar se o Secretariado Executivo é considerado uma profissão ou ocupação, as entrevistadas foram convidadas a fazer essa avaliação. A Entrevistada 1 caracterizou o Secretariado Executivo como profissão: "Pra mim secretário é profissão, sempre vai ser profissão", no entanto, relatou que nem todos seus colegas compartilham da mesma opinião: "Só que igual eu estou te falando, o próprio profissional da nossa área ele acha que é ocupação".A mesma Entrevistada 1 definiu profissão como "aquilo que você tem, $e h$, algo que você tem pro resto da sua vida, no sentido de você ter tido condições de se capacitar pra isso, tido condições de estudar, de se envolver, de qualificar cada vez mais".

A Entrevistada 2 também conceitua o Secretariado Executivo como uma profissão: "Eu analiso como profissão, eu vejo como profissão. Eu entendo que o profissional de secretariado, ele, em sua formação, ele recebe uma formação estratégica." Porém, assim como a Entrevistada 1, apresenta certa ambiguidade: "Talvez o próprio profissional de secretariado, o estudante em formação, ele não dê valor pra esse ingresso estratégico dentro do mercado de trabalho."

A Entrevistada 3 reafirma o exposto pelas outras entrevistadas: "é como uma profissão, até porque a gente tem uma lei de regulamentação pra profissão, neh?” Justificando que: "Tem, $e h$, a regulamentação, e têm diretrizes, tem todo o perfil, eh, voltado pro lado profissional, eh, pra profissão".

A definição das entrevistadas sobre profissão corresponde a um dos pontos levantados por Freidson (1986) quando aponta que a credencial utilizada para amparar sua reserva de mercado de trabalho é criada por um programa de treinamento que se desenrola fora do mercado, em escolas associadas a universidades.

A Entrevistada 1 complementou que "um cargo é aquilo que você ocupa numa empresa, ocupação". E concluiu que, "então, $e h$, a profissão é algo que fica, aquilo que eu tenho, é meu, agora cargo, ocupação, eu posso ter vários".

A justificativa usada pelas entrevistadas para amparar que o Secretariado Executivo é uma profissão está em conformidade com a literatura consultada, ou seja, a ideia de 
capacitação e estudo inerentes a uma profissão. Porém, só isso não é suficiente para alegar que o Secretariado Executivo seja uma profissão; deve-se considerar que esses pontos fazem parte de uma teoria dotada de outras características.

\section{CONSIDERAÇÕES FINAIS}

O objetivo geral deste artigo foi averiguar se o Secretariado Executivo no Brasil é uma profissão ou uma ocupação. Este foi alcançado por meio do levantamento dos dados, podendo, assim, concluir que, a partir da região estudada, o Secretariado Executivoainda é uma ocupação.

Após levantamento e estudo da literatura sobre profissão e ocupação, verificou-se que a principal característica de uma profissão é o conhecimento específico, adquirido nas escolas de treinamento e nas universidades (Macdonald, 1995; Freidson, 1986; Wilensky, 1964). Contudo, não podemos afirmar que apenas esse conhecimento garanta à ocupação o status e as implicações de uma profissão. Dessa forma, foi realizado um levantamento da teoria, a fim de abordar o estudo de diferentes autores acerca das profissões e ocupações, finalizando com a elaboração do Quadro de referência das profissões. Esse Quadro, ao reunir pontos convergentes das teorias, abrange a influência do conhecimento formal, da política, da relação entre profissões e mercado, da proteção e fechamento social sobre as profissões. Por isso, ele foi utilizado como base para as análises dessa pesquisa.

O primeiro ponto tido como caracterizador de uma profissão é a jurisdição exclusiva apontada por Wilensky (1964), Abbott (1988) e Macdonald (1995). Assim, a partir da análise das vagas de emprego e das entrevistas, foi possível verificar que o Secretariado Executivo não possuiu essa jurisdição, fato que pode ser justificado pela falta de controle do órgão responsável.

O segundo ponto qualificador de uma profissão é a educação como pré-requisito para a empregabilidade, destacado por Wilensky (1964), Freidson (1986) e Freeman (1997). Ao analisar as vagas de emprego, constatou-se que das 51 apenas $29 \%$ tinham como pré-requisito a formação exclusiva em Secretariado. Além disso, os próprios representantes que atuam nos sindicatos confirmaram que, devido à falta de um órgão fiscalizador, outros profissionais atuam no campo secretarial. A Entrevistada1 afirmou que sem essa fiscalização, "fica aíà mercê da vontade de quem queira empregar qualquer profissional pra secretário"; já a Entrevistada2 colocou que "então aqueles que têm formação, eles não, eh, acabam sendo desprestigiados por formações em outras áreas". 
A partir dessas respostas remetemos ao postulado por Macdonald (1995): se uma ocupação consegue estabelecer um curso superior como pré-requisito, isso é bom para os negócios e promove a garantia das habilidades do profissional. Apesar de o curso de Secretariado Executivo, em nível superior, ter sido criado em 1969, e atualmente, ser oferecido em 228 instituições, de acordo com informações do MEC, detectou-se que os bacharéis ainda não têm exclusividade no mercado de trabalho.

O terceiro ponto caracterizador de uma profissão trata-se de garantir a proteção da área de trabalho através da lei e da sustentação do código de ética, como apresentado por Wilensky (1964). O levantamento bibliográfico possibilitou verificar que a lei que regulamenta a área secretarial é a Lein 7.377 de 1985, com alterações dadas pela Lei no 9.261 de 1996. Apesar de haver essa lei regulamentadora, como o Secretariado Executivo não possui um Conselho, cabe ao MTE a fiscalização da área. Entretanto, como exposto pela Entrevistada 2 "o MTE não tem gente suficiente e não se interessa em fiscalizar a profissão de secretariado porque eles têm muitas outras atribuições". Já a Entrevistada 1relatou: "nós não temos autoridade pra fazer isso [controlar o ingresso de profissionais inabilitados na área secretarial], nem os nossos sindicatos no Brasil, nem a Federação”. Vale ressaltar o exposto por Wilensky (1964): em casos onde a área de competência não é claramente exclusiva, o objetivo será a proteção do título, a proteção legal é uma questão muito importante para novas profissões.

A última característica de uma profissão é dada pela criação de associações ou organizações profissionais que assumam um projeto de mercado, defendida por Wilensky (1964) e Freidson (1986). Freidson (1986) defende que essa deve ser uma organização coerente, que assuma efetivamente um projeto de mercado, que obtenha êxito em conquistar abrigo nesse mercado, controle e sinecura para seus integrantes. Wilensky (1964) destaca ainda que ativistas dentro dessas associações estão engajados em questões como se a ocupação é ou não uma profissão, quais são as atividades inerentes a ela, como melhorar a qualidade dos "recrutados", entre outras.

Como observado no referencial, as associações de classe da área secretarial surgiram na década de 1960, já em 1987, com o enquadramento sindical, foi possível a organização das associações em sindicatos, trazendo mais autonomia para elas, e em 1988, com número de sindicatos superior a cinco, foi instituída a Fenassec, contudo esta não tem poder de regulamentação e fiscalização.

Respondendo a um dos objetivos propostos neste artigo, foi possível constatar que o CFSEC seria o órgão regulador que garantiria controle total legalmente estabelecido à área 
secretarial, pois o exercício das atividades secretariais por trabalhador sem formação para tal e sem registro passaria a ser ilícito.

Wilensky (1964) reafirma o papel dessas associações ao expor que o projeto de mercado é acompanhado pelo processo de separar os competentes dos não competentes para realização das atividades. E conclui que "isso envolve uma melhor definição das atividades essenciais a uma profissão, do desenvolvimento de conflito interno entre os profissionais com diferentes bases de conhecimento e competição entre outros grupos que realizam atividades semelhantes”. Isso reforça, pois, os benefícios que o CFSEC traria à área.

À luz da teoria das profissões no que se refere à sociologia, conclui-se que, diferentemente da opinião das entrevistadas, o Secretariado Executivo no Brasil, considerando a região estudada, ainda é uma ocupação; contudo esta segue em processo de profissionalização. A afirmação sobre o processo de profissionalização pode ser feita com base na descrição feita por Wilensky (1964): desenvolvimento de trabalho em tempo integral, criação de escolas de treinamento, promoção de uma organização mais efetiva, proteção legal do monopólio, seguida pela adoção de um código de ética formal.

Dessa forma, percebe-se que o Secretariado Executivo passou e passa pelas fases do processo de profissionalização, mas que ainda não garantiu a proteção legal do monopólio. Também foi possível levantar que isso decorre do fato de não haver um órgão regulador e fiscalizador, nesse caso, o Conselho Federal de Secretariado. Ainda é preciso mais articulação política e proteção da área de trabalho por meio da lei, que garanta a dominância numérica do mercado e, consequentemente, maior reconhecimento aos trabalhadores capacitados para o exercício.

Acredita-se que este artigoapresente uma contribuição importante para o campo secretarial, para o fortalecimento da área acadêmica e para os que trabalham como Secretários Executivos. Entretanto, a maior contribuição, de fato, para a área, deve vir dos estudantes e trabalhadores. Considera-se que apenas o engajamento da área na busca por apoio político poderá concretizar a criação do CFSEC e, consequentemente, elevar a ocupação ao nível de profissão.

Além disso, ao analisar o histórico da atividade secretarial e das conquistas obtidas, evidencia-se que a atuação dos trabalhadores e órgãos de classe sempre foi essencial na busca por melhorias, contudo, falta participação e atuação dos estudantes. Faz-se necessário que estes se filiem aos sindicatos e sejam integrantes ativos no campo secretarial. Espera-se que as questões aqui discutidas possam subsidiar futuros trabalhos na área secretarial e que despertem maior interesse e participação por parte dos acadêmicos e trabalhadores. 


\section{Referências}

Abbott, Andrew (1988). The system of professions: an essay on the division of expert labor.University of Chicago Press: Chicago.

Alves-Mazzotti, Alda Judith \& Gewandsznajder, Fernando (2004). O método nas ciências naturais e sociais: pesquisa quantitativa e qualitativa. São Paulo: Pioneira Thomson Learning.

Bardin, Laurence (2011). Análise de conteúdo. São Paulo: Edições 70.

Bruno, Ivone Maria (2006). O poder de influência do profissional de secretariado no processo decisório das organizações. Programa de Mestrado em Administração - Dissertação - PUC, São Paulo.

Damarin, Amanda Kidd (2006). Rethinking occupational structure: the case of web site production work. Work and Occupations. Sage Journals.

Denzin, Norman K. et al. (2006). O planejamento da pesquisa qualitativa: teorias $e$ abordagens. Porto Alegre: Artmed.

E-MEC. Instituições de Educação Superior e Cursos Cadastrados. Recuperado em 12 setembro, 2014, de http://emec.mec.gov.br/

Fenassec. Federação Nacional das Secretárias e Secretários. Recuperado em 19 março, 2014, de http://www.fenassec.com.br/

Figueiredo, Vânia (1987). E a luta começou in dicas e dogmas. Thesaurus. Recuperado em 19 março, 2014, de http://www.sinsesp.com.br/artigos/historico/182-e-a-luta-comecouextraido-do-livro-dicas-e-dogmas-de-vania-figueiredo-1987

Fonseca, Wilson Corrêa da, Jr. Análise de conteúdo (2009). In: Duarte, Jorge e Barros, Antonio (Org.). Métodos de pesquisa em comunicação (2aed.) São Paulo: Atlas.

Freeman, Mike (1997). Is librarianship in the UK a true profession, a semi-profession or a mere occupation?(Volume 98) MCB University Press.

Freidson, Eliot (1986). Professional powers: a study of institutionalization of formal knowledge. The Universityof Chicago Press: Chicago.

- (1995). Para uma análise comparada das profissões. A institucionalização do discurso e do conhecimento formais. Tradução Filho Martins, João Roberto. Recuperado em 27 março, 2014,2 de http://www.anpocs.org.br/portal/publicacoes/rbcs_00_31/rbcs31_08.htm

Hall, R. (1969). Occupations and the social structure. Englewood Cliffs, Prentice-Hall.

Krause, Elliott A. (1971). The sociology of occupations. Boston: Little Brown. 
Lakatos, Eva Maria \& Marconi, Marina de Andrade (1991).Fundamentos de metodologia científica(3a ed.).São Paulo: Editora Atlas.

. (2011). Técnicas de pesquisa. (7a ed.) São Paulo: Atlas.

Lei $n^{\circ}$ 9.261, de 10 de janeiro de 1996 (1996). Altera a redação dos incisos I e II do art. 2º, o caput do art. $3^{\circ}$, o inciso VI do art. $4^{\circ}$ e o parágrafo único do art. $6^{\circ}$ da Lei ${ }^{\circ} 7.377$, de 30 de setembro de 1985. Recuperado em 15 abril, 2014, de http://www.planalto.gov.br/ccivil_03/leis/L9261.htm

Macdonald, Keith M. (1995). Thesociologyoftheprofessions.London: SagePublications.

Ministério da Educação. Institui as Diretrizes Curriculares Nacionais para o curso de graduação em Secretariado Executivo e dá outras providências. Resolução $n^{o} 3$, de 23 de junho de 2005.Recuperado em 18 abril, 2014, de http://portal.mec.gov.br/cne/arquivos/pdf/rces003_05.pdf

Ministério do Trabalho e Emprego. Classificação Brasileira de Ocupações. Códigos, Títulos e Descrições. Livro 1, 2002. Recuperado em 4 setembro, 2014, de http://www.sine.rn.gov.br/contentproducao/aplicacao/sine/arquivos/pdf/cbo2002livro1.pdf

Nonato Jr., R. (2009). Epistemologia e teoria do conhecimento em secretariado executivo: a fundação das ciências da assessoria. Fortaleza: Expressão Gráfica.

Queiroz, Antônio Augusto de (2003). A luta das secretárias pelo conselho profissional. $\begin{array}{lllll}\text { Recuperado em } & 11 & \text { setembro, } & 2014, & \text { de }\end{array}$ http://www.sinsesp.com.br/images/pdf/conselhoprofissional.pdf

Sabino, Rosimeri Ferraz \& Marchelli, Paulo Sérgio (2009). O debate teórico-metodológico no campo do secretariado: pluralismos e singularidades.Cadernos Ebape. BR, vol. 7, $\mathrm{n}^{\mathbf{0}}$ 4, artigo 6, Rio de Janeiro.

Santana, Marco Aurélio \& Ramalho, José Ricardo (2009). Sociologia do trabalho (2a ed.). Rio de Janeiro: Jorge Zahar Editora.

Scott, John \&Marshall, Gordon (2009).A dictionary of sociology. Nova York: Oxford University Press.

Watson, Tony (1995). Sociology, work and industry. London: Routledge.

Wilensky, Harold L. (1964).The profissionalization of everyone? The American Journal of Sociology, vol. 70, $\mathrm{n}^{\mathrm{o}} 2$, pp. 134-158.

Zuin, Débora Carneiro (2012). Revisiting the study of occupations:a holistic view of contemporary secretarial work. Tese de doutorado. Edinburgh: The University of Edinburgh. 